\title{
Receptor activator of NF-kB ligand enhances the activity of macrophages as antigen presenting cells
}

\author{
Hyewon Park ${ }^{1}$, Ok-Jin Park ${ }^{1}$, \\ Jieun $\operatorname{Shin}^{1}$ and Youngnim Choi ${ }^{1,2}$ \\ ${ }^{1}$ Department of Oromaxillofacial Infection and \\ Immunity and Dental Research Institute \\ School of Dentistry, Seoul National University \\ Seoul 110-749, Korea \\ ${ }^{2}$ Corresponding author: Tel, 82-2-740-8643; \\ Fax, 82-2-743-0311; E-mail, youngnim@snu.ac.kr
}

\section{Accepted 28 September 2005}

Abbreviations: BMM, bone marrow-derived macrophage; CD40L, CD40 ligand; iNOS, inducible nitric oxide synthase; MCP-1, monocyte chemotactic protein-1; RANKL, receptor activator of NF-KB ligand; TNFR, TNF receptor

\begin{abstract}
Receptor activator of NFKB ligand (RANKL) is known as a key regulator of osteoclastogenesis. However, the fact that fibroblasts and periodontal ligament cells express RANKL in response to bacterial sub stances, suggests that RANKL may have evolved as a part of the immunity to infection. As RANKL increases the survival and activity of dendritic cells, it may have similar effects on macrophages. To address this issue, we studied the effect of RANKL on various functions of macrophages using mouse bone marrow derived macrophages. RANKL en hanced the survival of macrophages and up-regulated the expression of CD86. RANKL-treated macro phages showed increased allogeneic $T$ cell activation and phagocytic activity compared to control cells. In addition, RANKL increased the expression of TNF $\alpha$, MCP-1, and IL- 6 but not of IL-10, IL-12, IFN- $\gamma$, and iNOS. Collectively, RANKL augmented the activity of macrophages especially as antigen presenting cells, suggesting its new role in immune regulation.
\end{abstract}

Keywords: antigen presentation; CD86 antigen; cell survival; cytokines; macrophages; MHC class II; TRANCE protein

\section{Introduction}

Receptor activator of NF-KB ligand (RANKL), a member of the TNF family, is known as the key regulator of osteoclastogenesis (Kong et al., 1999). RANKL expressed on the surface of osteoblasts and stromal cells or soluble recombinant RANKL, supports osteoclast differentiation and activates mature osteoclasts to resorb bone in vitro (Lacey et al., 1998; Yasuda et al., 1998; Shin et al., 2003). Recently, several groups examined that bacteria or bacterial components induce the expression of RANKL from gingival fibroblasts, periodontal ligament cells, and synovial fibroblasts (Tiranathanagul et al., 2004; Zhang et al., 2004; Belibasakis et al., 2005). Monocytes and macrophages can differentiate into osteoclasts under a suitable condition prepared in vitro (Udagawa et al., 1990; Shin et al., 1995; Yasuda et al., 1998). RANKL expressed on gingival or sinovial fibroblasts may direct macrophages present in connective tissue and monocytes recruited from blood to differentiate into osteoclasts, which leads to bone destruction in periodontitis or arthritis. However, more reasonable interpretation seems that RANKL is induced in extra-skeletal tissues upon microbial infection as a part of immune response to control the infection and osteoclastogenesis may occur as a side effect. It raised a question what would be the role of RANKL in immune response to microbes.

RANKL is expressed also on activated T cells, and a major target for RANKL in the immune system appears to be mature dendritic cells that express a high level of RANK (Anderson et al., 1997; Wong et al., 1997a). RANKL promoted the survival of mature dendritic cells and enhances the ability of dendritic cells to stimulate naive $T$ cell proliferation in a mixed leukocyte reaction (Anderson et al., 1997; Wong et al., 1997b). In addition, RANKL induced the production of proinflammatory cytokines (IL-1 and IL-6) and cytokines that direct differentiation of $T$ cells, such as IL-12 and IL-15 from dendritic cells (Josien et al., 1999). Treatment of antigen-pulsed mature dendritic cells with RANKL prior to subcutaneous injection into recipient mice resulted in increase in both primary and memory $\mathrm{T}$ cell immune responses in vivo (Josien et al., 2000). RANKL induced on fibroblasts by bacterial components may activate dendritic cells in situ and subsequent adaptive immunity as known before. Similarly, RANKL may also activate macrophages because RANKL and RANK have the highest sequence homology to CD40 ligand (CD40L) and CD40, respectively among TNF/ 
TNF receptor (TNFR) family members (Anderson et al., 1997), which provide an important signal during activation of macrophages by Th1 cells. The major function of macrophage in extraskeletal tissues upon infection is the removal of microbes by phagocytosis and the presentation of antigens to $T$ cells. Although dendritic cells are the most powerful T-cell stimulator especially in response to viruses, macrophages have an important role in presenting particulate antigens and extracellular pathogens including most bacteria (Janeway et al., 2005).

Although the role of RANKL in the differentiation of osteoclasts from macrophages has been studied extensively, its effect on macrophage function per se is not known. To address this issue, we studied the effect of RANKL on the various functions [survival, phagocytosis, antigen presentation, cytokine secretion, inducible nitric oxide synthase (iNOS) expression] of macrophages.

\section{Materials and Methods}

\section{Preparation of bone marrow derived macrophages (BMMs)}

Macrophages were prepared from mouse bone marrow cells as described previously (Fox and Chambers, 2000). Briefly, bone marrow cells from C57BL/6 mice (Samtaco, Kyung-gi, Korea) were flushed from long bones, suspended in complete $\alpha$-MEM medium containing $10 \%$ FBS supplemented with $1 \mathrm{ng} / \mathrm{ml}$ murine monocytecolony-stimulating factor (M-CSF) (Peprotech, Rocky Hill, NJ). After one-day incubation, non-adherent bone marrow (BM) cells were cultured in fresh medium with 20 $\mathrm{ng} / \mathrm{ml} \mathrm{M}-\mathrm{CSF}$ for another two days to generate BMMs. On day three, non-adherent cells were washed away and remaining BMMs were subjected to various stimulation.

\section{Cell survival}

Non-adherent BM cells were plated at $1 \times 10^{5}$ cells/ well into 96-well plates, cultured with $20 \mathrm{ng} / \mathrm{ml} \mathrm{M}$ CSF for two days to generate BMMs, and then washed with PBS twice. Cells were cultured with fresh culture medium alone or medium containing the various amounts of RANKL (Peprotech). After 24, 48 and 72 h culture, SYTOX green (Molecular Probe, Eugene, OR, USA) was added to each well to make $5 \mu \mathrm{M}$ and the fluorescence intensity was measured with a fluorometer (BMG Labtech, Offenburg, Germany). Autofluorescence measured before adding SYTOX green was subtracted from the fluorescence with SYTOX green, and cell death was expressed as a ratio to control wells cultured for $24 \mathrm{~h}$.

\section{Annexin-V assay}

Non-adherent BM cells were plated at $4 \times 10^{5}$ cells/well into 24-well plates, cultured with $20 \mathrm{ng} / \mathrm{ml}$ M-CSF for two days to generated BMMs, and then washed with PBS twice. BMMs were cultured with fresh culture medium alone or medium containing the various amounts of RANKL for $6 \mathrm{~h}$. Cells were harvested and transferred to FACS tubes. After wash, cells were incubated with Annexin-V-FITC (BD Biosciences, San Diego, CA) and propidium iodide (PI from Molecular Probe) in binding buffer (10 mM Hepes/NaOH, pH 7.4, $140 \mathrm{mM} \mathrm{NaCl}, 2.5$ $\mathrm{mM} \mathrm{CaCl}$ ) for $15 \mathrm{~min}$, and immediately analyzed with FACSCalibur (BD Bioscience).

\section{Staining of surface markers and intracellular iNOS}

BMMs were stimulated with various cytokines of indicated concentrations: IFN- $\gamma$ (Peprotech) or Escherichia coli LPS (Sigma, St. Louis, MO) in the absence or presence of RANKL (50 ng/ml). After 24 or $48 \mathrm{~h}$ culture, cells were harvested with a cell scraper, transferred to FACS tube, washed, and stained with anti-CD86 mAb clone GL-1-PE (BD Bioscience) and anti-I-A/I-E mAb clone 2G9-FITC (BD Bioscience). For intracellular iNOS stain, cells were fixed and permeabilized with Fix/Perm solution (BD bioscience), stained with anti-iNOS mAb clone 6-FITC, and washed with Perm/Wash solution (BD bioscience). Cells stained with appropriate FITC or $\mathrm{PE}$ conjugated isotype control Abs served as a negative control.

\section{Mixed leukocyte reaction}

For mixed leukocyte reaction, BMMs were obtained by plating $2.56 \times 10^{5}$ and serially diluted nonadherent bone marrow cells/well into 48-well plate in triplicate and subsequent culture with $20 \mathrm{ng} / \mathrm{ml}$ $\mathrm{M}$-CSF for $48 \mathrm{~h}$. BMMs were washed and stimulated with complete medium alone or medium containing $50 \mathrm{ng} / \mathrm{ml}$ RANKL for $24 \mathrm{~h}$. Lymph node $\mathrm{T}$ cells isolated from ICR mouse (Samtaco) were labeled with $5 \mathrm{mM}$ CFSE (Molecular Probe) by incubating for $5 \mathrm{~min}$ at room temperature and subsequent wash with PBS. After T cells $\left(1 \times 10^{6}\right.$ cells/well) were co-cultured with BMMs for 3 days, $T$ cells were harvested, and fixed with $70 \%$ ethanol in PBS. The cells were stained with PI, and analyzed by flow cytometry. The percentage of proliferated cell was calculated as the sum of cells in R2 ( $G 1$ cells with reduced CFSE content) and R3 (cells in S/G2/M phase). 


\section{Phagocytosis assay}

BMMs were stimulated with culture medium alone or medium containing $50 \mathrm{ng} / \mathrm{ml}$ RANKL, $4 \mathrm{ng} / \mathrm{ml} \mathrm{IFN}-\gamma$, $1 \mathrm{ng} / \mathrm{ml}$ LPS, RANKL plus IFN- $\gamma$, or RANKL plus LPS for 24 h. E. coli DH5- $\alpha$ grown in LB broth were harvested during exponential growth, fixed in ethanol, labeled with $5 \mu \mathrm{M}$ CFSE, then added to stimulated BMMs. Cells were incubated at $37^{\circ} \mathrm{C}$ for $0.5,4$ or $7 \mathrm{~h}$. After incubation, the cells were harvested and incubated with trypan blue (Gibco, Grand Island, NY) for 2 min to quench the fluorescence of bacteria bound on the cell surface. Then, cells were washed with PBS once and analyzed by flow cytometry.

A

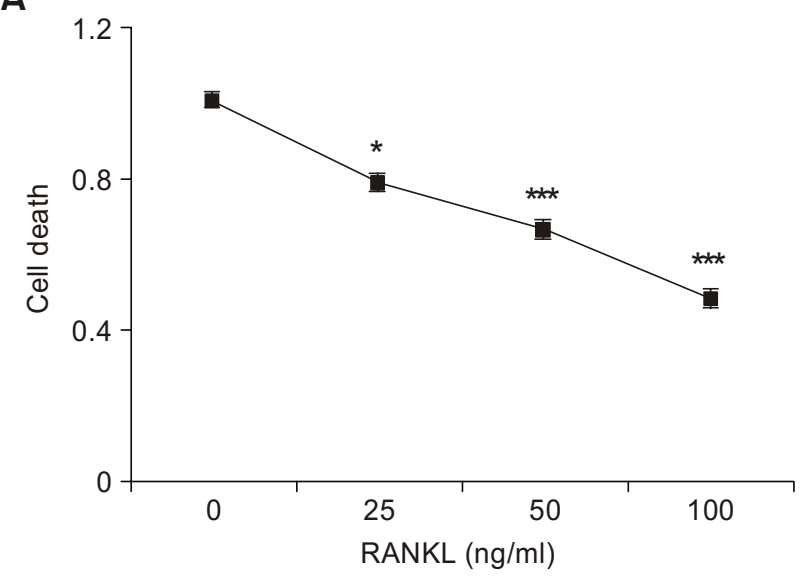

B

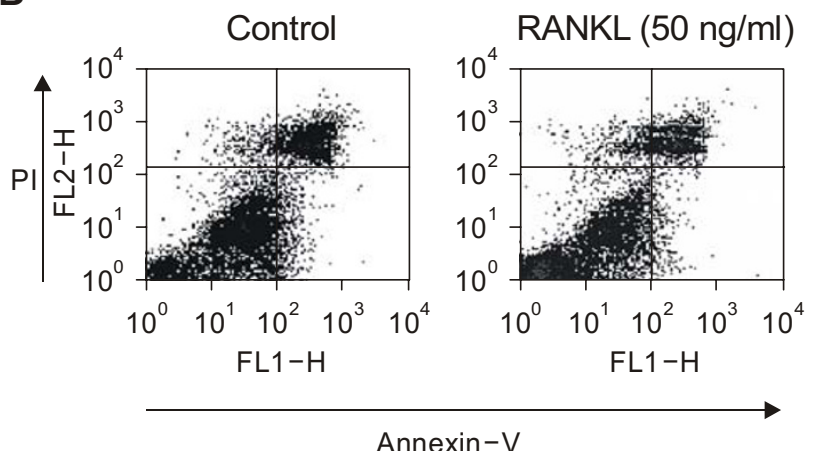

\section{Measurement of cytokine induction}

BMMs were stimulated with complete medium alone or medium containing $50 \mathrm{ng} / \mathrm{ml}$ RANKL, $4 \mathrm{ng} / \mathrm{ml}$ IFN- $\gamma, 1 \mathrm{ng} / \mathrm{ml}$ LPS for $24 \mathrm{~h}$. Then, cell supernatants were collected, and pro-inflammatory cytokines secreted into medium were measured using a mouse inflammation cytometric bead array kit (BD Bioscience) according to the manufacturer's direction.

\section{Statistics}

All presented data are the representative of two to three experiments with similar results. Student's $t$-test was performed to compare the means of two groups.
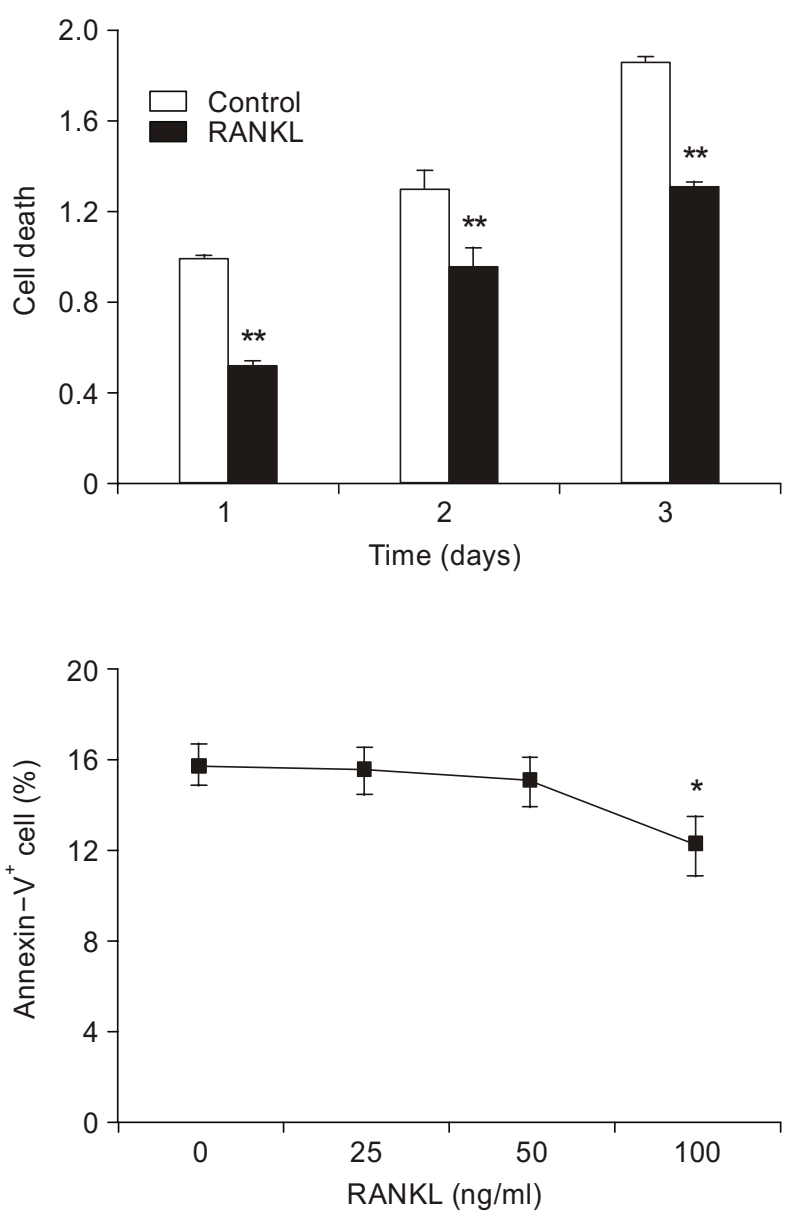

Figure 1. Effect of RANKL on macrophage survival. (A) Non-adherent BM cells were plated at $1 \times 10^{5}$ cells/well into 96 -well plates, cultured with 20 $\mathrm{ng} / \mathrm{ml} \mathrm{M}$-CSF for 2 days to generated BMMs, and then washed with PBS twice. BMMs were further cultured with fresh culture medium alone or medium containing the various amounts of RANKL for $24 \mathrm{~h}$ (left panel) or medium with or without $100 \mathrm{ng} / \mathrm{ml}$ RANKL for 24,48 , and $72 \mathrm{~h}$ (right panel). Cells were stained with $5 \mu \mathrm{M}$ SYTOX green and the fluorescence intensity was measured with a fluorometer. Cell death was expressed as a ratio to control wells cultured for $24 \mathrm{~h}$. Each point represents the mean and SEM of four wells. (B) BMMs were cultured with fresh culture medium alone or medium containing the various amounts of RANKL for $6 \mathrm{~h}$. Cells were harvested, stained with Annexin-V-FITC and PI, and immediately analyzed by flow cytometry. Typical dot plot analyses are shown at left panel. The sums of $\mathrm{Pl}^{+}$Annexin ${ }^{+}$and $\mathrm{Pl}^{-}$Annexin ${ }^{+}$cells are graphed at right panel. Each barpoint represents the mean \pm SEM of three cultures. ${ }^{*} P<0.05,{ }^{* *} P<0.01,{ }^{* *} P<0.0005$, versus control. 


\section{Results}

\section{RANKL is a survival factor for macrophages}

RANKL inhibits apoptosis and increases the survival of osteoclasts and dendritic cells by activating the anti-apoptotic serine/threonine kinase Akt/PKB (Anderson et al., 1997; Josien et al., 1999; Wong et al., 1999; Sakai et al., 2000; Arron et al., 2001; Xing et al., 2001). We examined if RANKL increases the survival of macrophages, too. Since macrophages differentiate into osteoclasts in the presence of M-CSF plus RANKL in vitro, we cultured bone marrow derived macrophages with medium alone or medium containing RANKL. Cell death was measured using SYTOX green that penetrates only damaged membrane and becomes fluorescent upon binding to DNA. Since SYTOX green does not require washing or cell transfer, it is very convenient and minimizes experimental errors caused by cell transfer. As shown in Figure $1 \mathrm{~A}$ left panel, the spontaneous cell death of macrophages was decreased by RANKL treatment in a dose dependent manner and the effect on cell survival was well observed by day 3 (Figure $1 \mathrm{~A}$, right panel). We further confirmed the effect of RANKL on macrophage survival by Annexin- $V$ assay. To observe early apoptotic cells, we incubated BMMs with medium alone or medium containing RANKL for $6 \mathrm{~h}$, and stained the cells with Annexin-V-FITC and PI. RANKL treatment also decreased the percentage of cells stained with Annexin- $\mathrm{V}$, indicating the antiapoptotic effect of RANKL (Figure 1B).

\section{Phagocytosis}

Macrophages ingest microbes through phagocytosis and present antigens to $T$ cells following antigen processing. Therefore, phagocytosis takes an important part in the function of macrophages as antigen presenting cells as well as effector cells. We measured the effect of RANKL on the phagocytic activity of macrophages. BMMs stimulated medium alone or medium containing RANKL $(50 \mathrm{ng} / \mathrm{ml})$ for $24 \mathrm{~h}$ incubated with CFSE-labeled E. coli particles. The fluorescence of $E$. coli bound on the cell surface was quenched with a vital dye trypan blue and the fluorescence of ingested bacteria was measured by flow cytometry. RANKL augmented phagocytosis by macrophages (Figure 2) but it did not act synergistically with either INF- $\gamma$ or LPS (data not shown).

\section{RANKL up-regulates the expression of MHC class II and CD86}

In order to present phagocytosed $\mathrm{Ag}$ to $\mathrm{T}$ cells properly, macrophages need to express MHC class

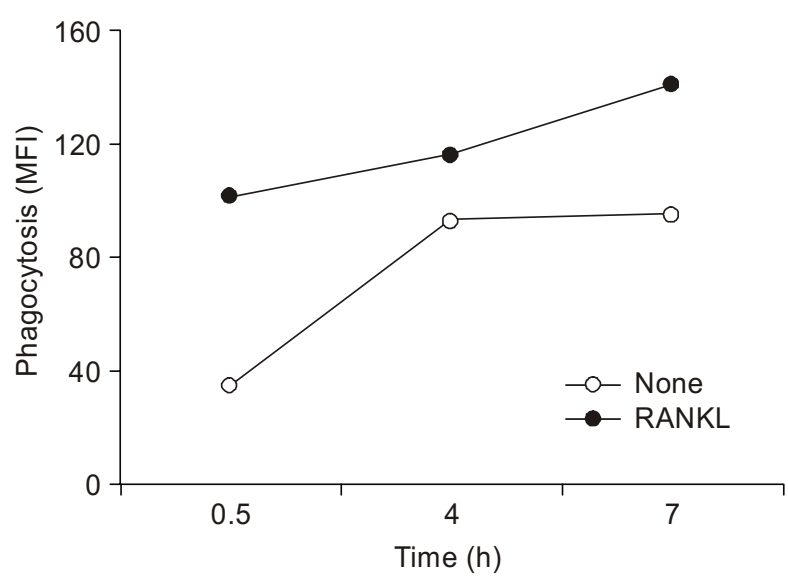

Figure 2. Effect of RANKL on phagocytic activity of macrophages. BMMs were stimulated with medium alone or medium containing 50 $\mathrm{ng} / \mathrm{ml}$ RANKL for $24 \mathrm{~h}$ and then incubated with CFSE-labeled $E$. coli at $37^{\circ} \mathrm{C}$ for $0.5,4,7 \mathrm{~h}$. The cells were harvested and the fluorescence of extracellular bacteria was quenched by incubating with trypan blue for 2 min. The fluorescence of ingested bacteria was measured by flow cytometry. Phagocytosis was expressed as the mean fluorescence intensity (MFI) of phagocytosing cells.

II molecules loaded with $\mathrm{Ag}$ and co-stimulatory molecules, CD80 or CD86. To study the effect of RANKL on antigen presenting function by macrophages, we examined the expression of MHC class II I-A/I-E and co-stimulatory molecule CD86 (B7-2). Small percentage of mouse bone marrow-derived macrophages expressed MHC class II and CD86 at low levels and RANKL treatment up-regulated them although the effect on the expression of MHC class II was minimal (Figure 3A). Upon infection, recognition of microbes and signaling through toll-like receptors by macrophages leads to the induction of MHC class II and co-stimulatory molecules on them. IFN- $\gamma$, the most important macrophage-activating cytokine has such a function, too. We examined how RANKL would work with either LPS or IFN- $\gamma$ to induce MHC class II and CD86. While E. coli LPS was a weak inducer, IFN- $\gamma$ was a robust inducer of both MHC class II and CD86 (Figure 3B). RANKL acted synergistically with both LPS and IFN- $\gamma$ to up-regulate CD86 markedly (Figure $3 C$ ). Only MHC class $~^{+}{ }^{+} \mathrm{CD} 86^{+}$double positive cells can present the antigens of phagocytosed microbes and activate $\mathrm{CD}^{+} \mathrm{T}$ cells properly. RANKL treatment enhanced not only the percentage of $\mathrm{MHC}$ class $\mathrm{II}^{+} \mathrm{CD} 86^{+}$cells but also the levels of expression for MHC class II and CD 86 by macrophages (Figure 3B, C), suggesting an increased ability to activate $T$ cells.

\section{RANKL-treated macrophages have an enhanced} ability to stimulate allogeneic $T$ cells

To verify the ability to activate $T$ cells, we co-cultured 
A

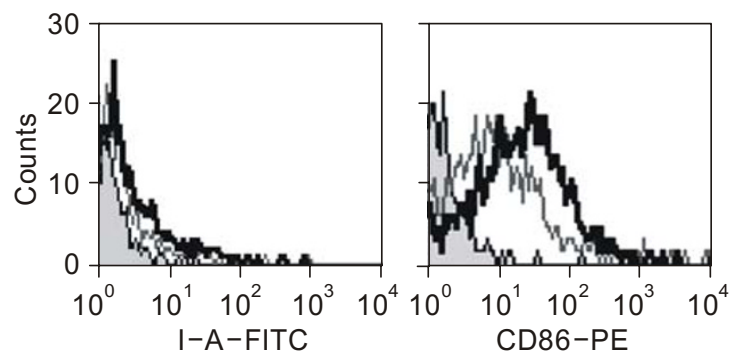

B

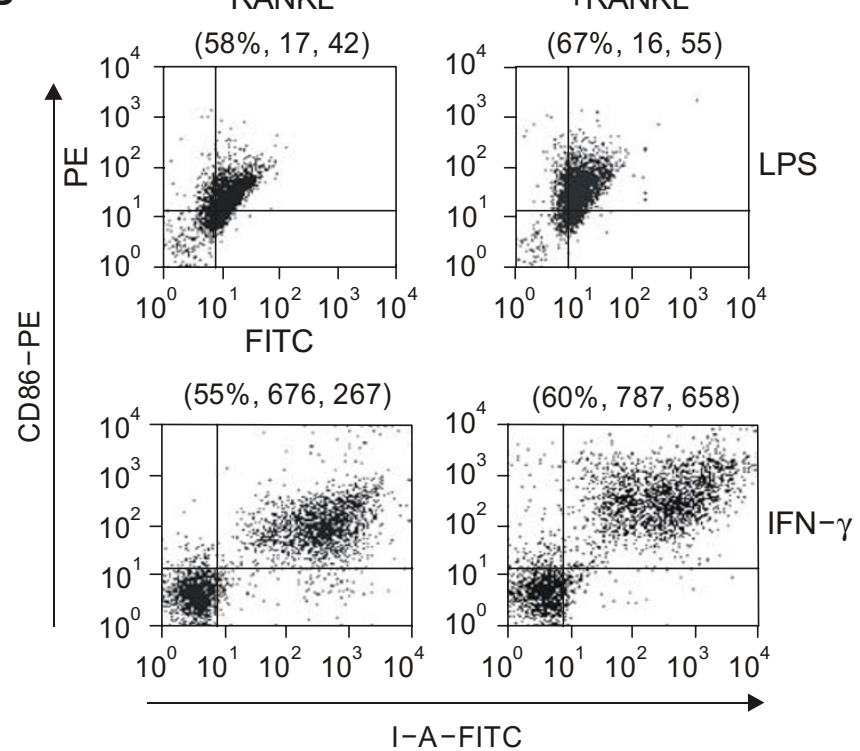

C
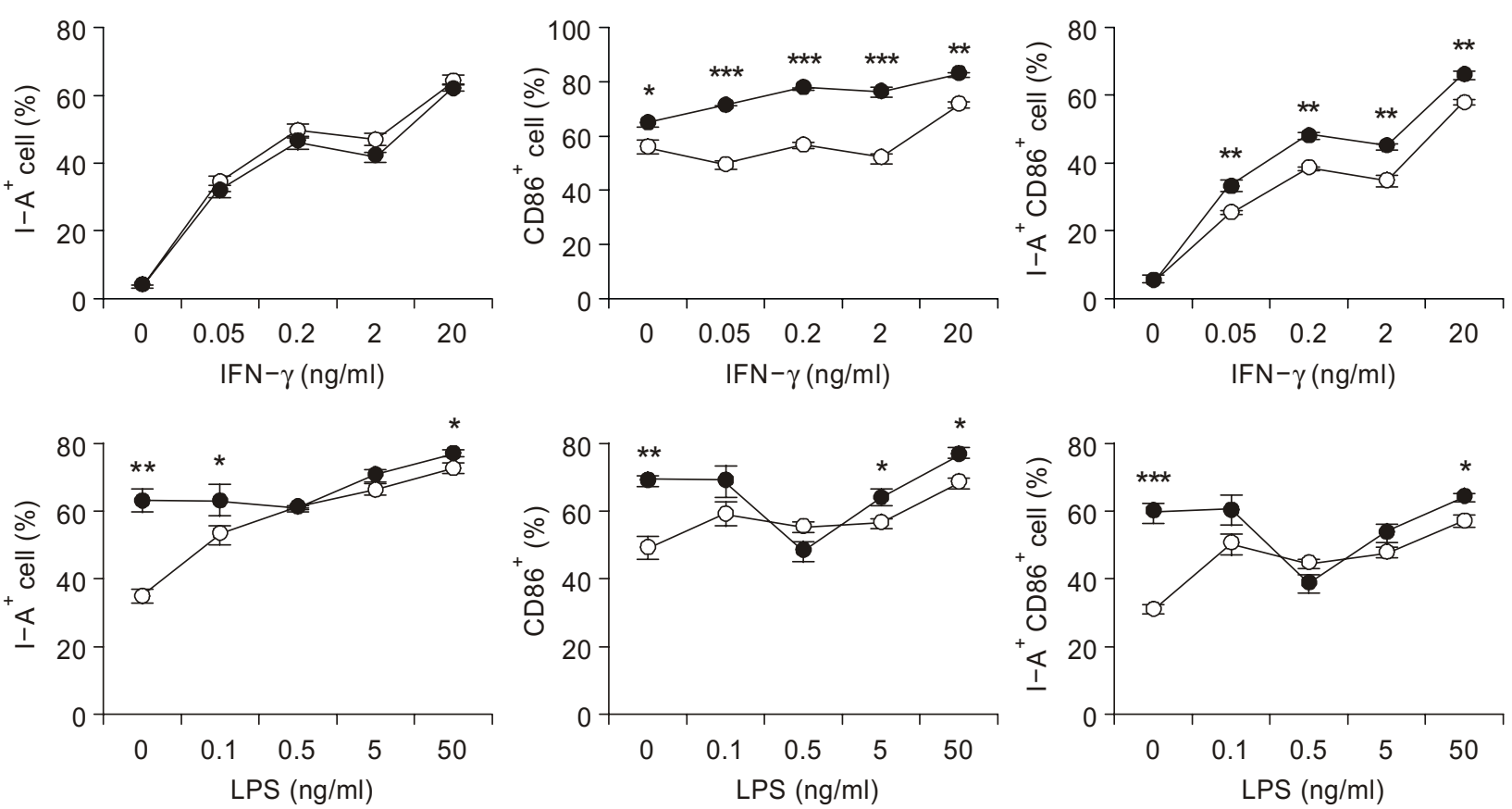

Figure 3. Effect of RANKL on the expression of MHC class II and CD86 by macrophages. (A) BMMs were stimulated with fresh medium alone or medium containing RANKL $(50 \mathrm{ng} / \mathrm{ml})$ for $24 \mathrm{~h}$. Cells were double stained with anti-I-A/l-E-FITC and anti-CD86-PE mAbs and analyzed by flow cytometry. Histograms of isotype control (filled), medium alone (thin gray line), and medium with RANKL (thick black line) were overlaid. (B, C) BMMs were stimulated with various amounts of IFN- $\gamma$ in the absence and presence of RANKL $(50 \mathrm{ng} / \mathrm{ml})$ for $24 \mathrm{~h}$ or with various amounts of LPS in the absence and presence of RANKL ( $50 \mathrm{ng} / \mathrm{ml})$ for $48 \mathrm{~h}$. Cells were double stained with anti-I-A/l-E-FITC and anti-CD86-PE mAbs and analyzed by flow cytometry. Dot plots of BMMs stimulated with $2 \mathrm{ng} / \mathrm{ml} \mathrm{IFN-} \gamma$ or $50 \mathrm{ng} / \mathrm{ml}$ LPS in the absence and presence of RANKL ( $50 \mathrm{ng} / \mathrm{ml}$ ) are shown (B). Numbers in parenthesis represent the percentage, $x$ mean, and y mean of upper right quadrant, respectively. The percentages of $I-A^{+}, C D 86^{+}$, and $I-A^{+} C D 86^{+}$cells in the absence (empty circle) and presence (filled circle) of RANKL are graphed (C). Each barpoint represents the mean \pm SEM of three cultures. ${ }^{*} P<0.05,{ }^{* *} P<$ $0.01,{ }^{* * *} P<0.001$, versus control.

macrophages derived from C57BL/6 with CFSElabeled $T$ cells from ICR mice for 3 days and analyzed cell cycle by flow cytometry. CFSE dye has been widely used in immunological laboratories around the world to monitor the proliferation of lymphocytes in vivo and in vitro (Lyons, 2000). The fluorescence 
A

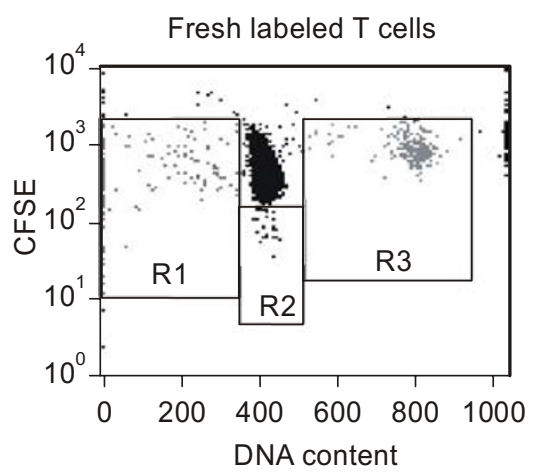

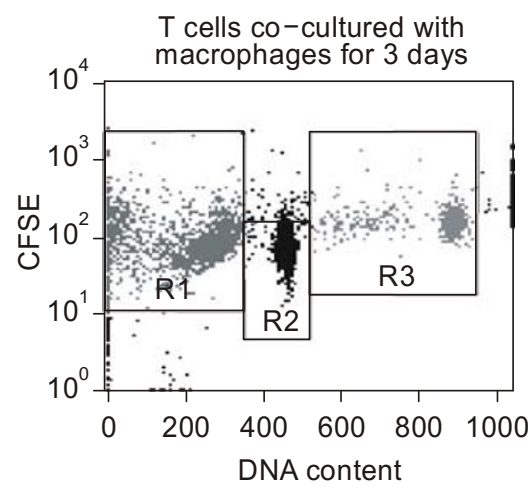

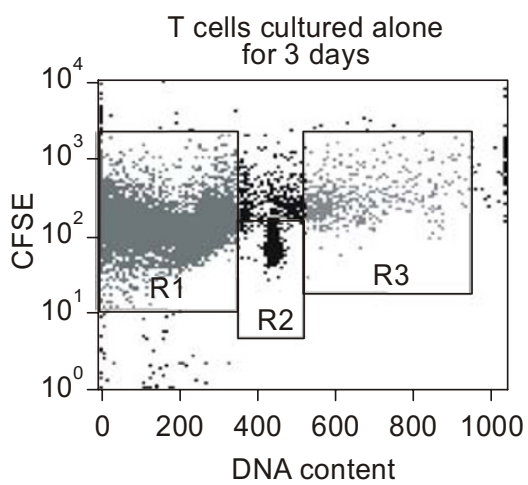

B
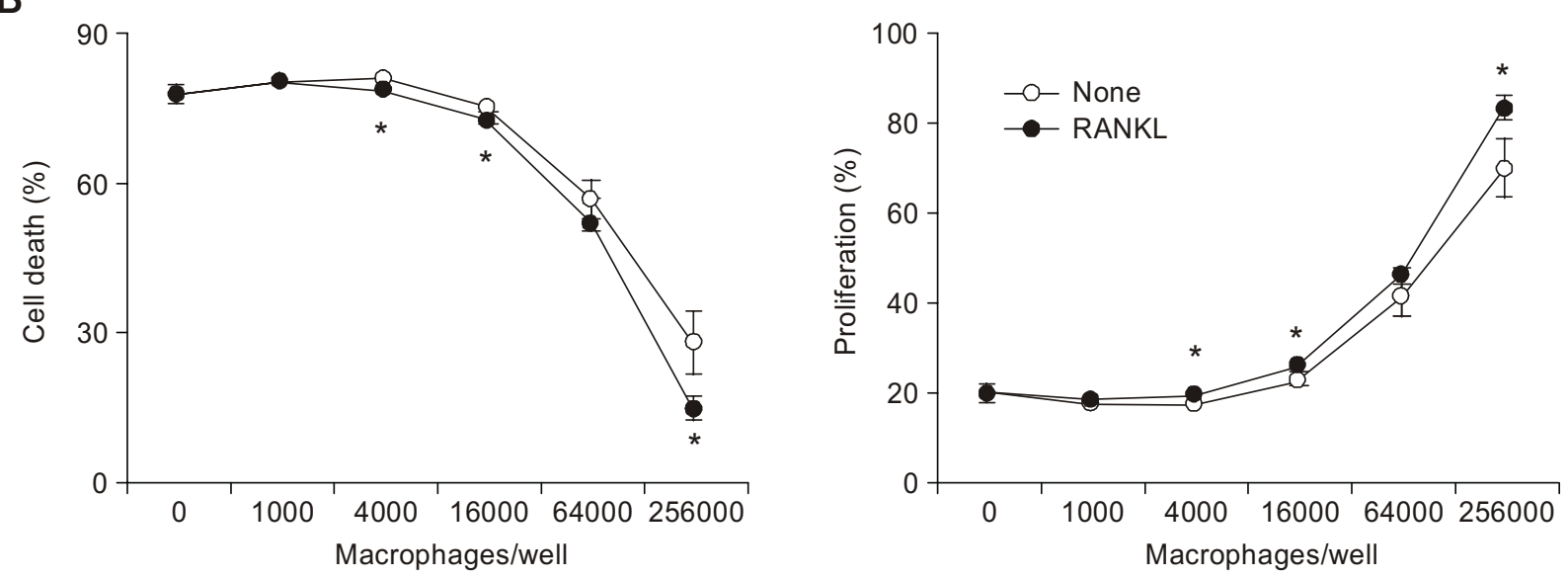

Figure 4. Effect of RANKL on the ability of macrophages to stimulate allogeneic T cells. BMMs were generated by plating $2.56 \times 10^{5}$ and serially diluted non-adherent BM cells into 48-well plate in triplicates and subsequently cultured with $20 \mathrm{ng} / \mathrm{ml}$ M-CSF for $48 \mathrm{~h}$. BMMs were stimulated with medium alone or medium containing $50 \mathrm{ng} / \mathrm{ml} \mathrm{RANKL}$ for $24 \mathrm{~h}$ and then co-cultured with CFSE-labeled lymph node T cells $\left(1 \times 10^{6}\right.$ cells/well) from ICR mouse for 3 days. DNA contents of T cells were stained with $\mathrm{PI}$, and cell cycle was analyzed by flow cytometry. (A) Dot plots to analyze cell cycle. R1 represents dead cells with subG $G_{0} G_{1}$ DNA content. $R 2$ represents cells in $G_{1}$ phase that went through cell division. $R 3$ represents cells in $S / G_{2} / M$ phase. (B) Dead cell \% and proliferated cell \% (R2 + R3) were calculated. ${ }^{*} P<0.05$, versus control.

intensity of CFSE is diluted serially by each cell division but the reduction of CFSE intensity by proliferation cannot be distinguished from that caused by cell death. In combination with cell cycle analysis based on DNA contents stained with $\mathrm{PI}$, we could determine the distribution of the cells in the respective cell cycle phases and the fraction of dead cells with hypodiploid DNA contents as well as proliferation (Tokalov et al., 2003). Before co-culture, most $T$ cells are not cycling $\left(\mathrm{G}_{0} / \mathrm{G}_{1}\right.$ phase) and all cells retain high CFSE intensity (Figure 4A, left panel). After co-culture with allogeneic macrophages, the percentage of cycling cells in $S / G_{2} / M$ phase (R3) was increased and most cells in the $G_{0} / G_{1}$ phase have the diluted CFSE intensity (R2) (Figure $4 \mathrm{~A}$, middle panel). Following 3 -day culture in the absence of allogeneic macrophages, only small percentage of the cells proliferated and most cells had subG ${ }_{0} / G_{1}$ DNA content (R1), suggesting that non-cycling cells undergo cell death (Figure 4A, right panel). RANKL treatment of macrophages before co-culture with $\mathrm{T}$ cells increased proliferation and decreased cell death (Figure 4B). These results confirmed that RANKL enhances the antigen presentation function of macrophages.

\section{Proinflammatory cytokines and iNOS}

We wondered if RNAKL activates the effector function of macrophages, too. We measured the secretion of pro-inflammatory cytokines. RANKL treatment increased the secretion of TNF- $\alpha$, MCP-1, and IL-6 $(P<0.05)$ (Figure 5A left). However, the degree of induction was very low compared to that obtained by either IFN- $\gamma$ or LPS. RANKL did not change the balance between Th1 and Th2 cytokines (Figure 5A right). In addition, RANKL did not induce iNOS expression, either (Figure 5B). These results 

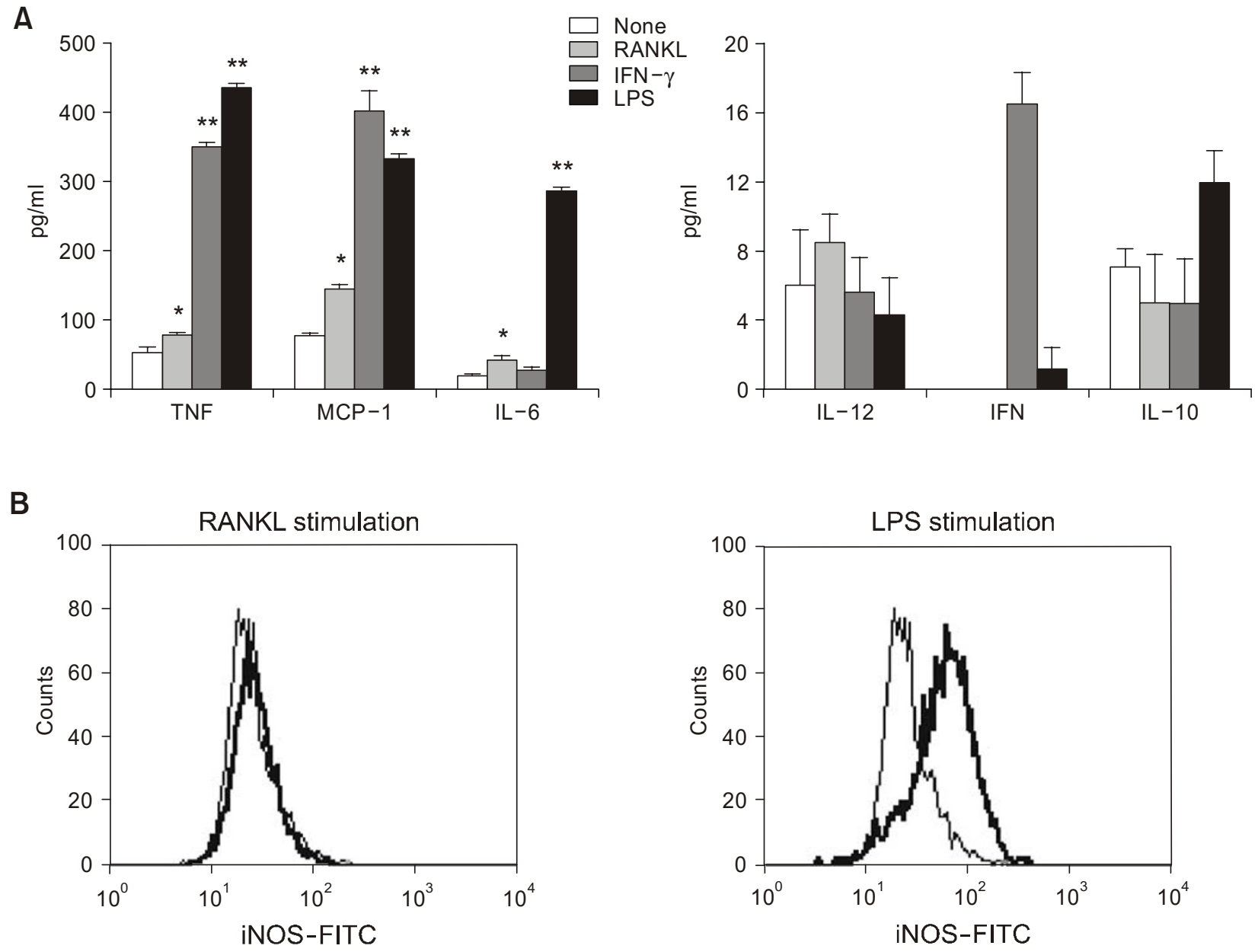

Figure 5. Effect of RANKL on Effector function of macrophages. BMMs were stimulated with medium alone or medium containing $50 \mathrm{ng} / \mathrm{ml} \mathrm{RANKL} 4$

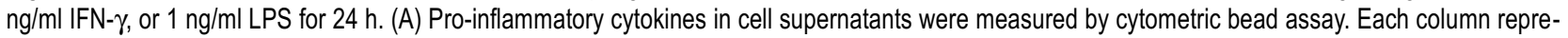
sents the mean and SEM of triplicate samples. ${ }^{*} P<0.05$, ${ }^{* *} P<0.0001$, versus control. (B) Cells were fixed, permeabilized and stained with a FITC-conjugated anti-iNOS mAb. The histograms of cells stimulated with medium alone (thin gray line), and medium with RANKL (thick black line) or LPS (thick black line) were overlaid.

indicated that RANKL does not have much effect on the effector function of macrophages.

\section{Discussion}

Collectively, we have shown that RANKL can enhance the survival of macrophages and increase their function as antigen presenting cells by enhancing CD86 expression and phagocytic activity. Recently, Bharti et al. reported that RANKL suppresses cell proliferation and induce apoptosis in mouse monocyte RAW 264.7 cells (Bharti et al., 2004). Since RAW 264.7 cells are established from tumor, those cells keep proliferation without M-CSF and differentiate into osteoclasts by culture with RANKL alone as they have also shown. Therefore, those results indicate that RANKL induces apoptosis in osteoclast precursors and osteoclasts rather than monocytes. The regulation of apoptosis of tumor cells should be very different from that of primary cells. Primary bone marrow derived macrophages do not proliferate in the absence of M-CSF (Lohmann-Matthes et al., 1991) and RANKL treatment decreased the apoptosis in our study (Figure 1B). In the presence of M-CSF, cell cycle withdrawal induced by RANKL is coordinated with differentiation into osteoclasts (Sanka et al., 2003).

Although macrophages differentiate into osteoclasts by M-CSF plus RANKL in vitro, there are evidences that osteoclasts are differentiated only around mineralized materials in vivo (Krukowski and Kahn, 1982; Glowacki et al., 1986; Goldring et al., 1988). Even in vitro, osteoclastogenesis did not 
occur efficiently in the semisolid culture system (Miyamoto et al., 2000). Furthermore, IFN- $\gamma$ directed macrophages to differentiate into giant cells rather than osteoclasts in the presence of M-CSF plus RANKL in vitro (Choi and Kim, 2003). Our results indicated that RANKL augments the function of macrophages as antigen presenting cells but not as effector cells. Therefore, RANKL induced by bacterial components in soft tissue may have an important role in the early phase of infection to induce proper adaptive immune response by facilitating antigen presentation. In addition, RANKL expressed on activated $T$ cells may also affect the duration and quality of macrophage-T cell interaction during antigen presentation. Our study suggests a new function of RANKL as an important link between innate and adaptive immunity.

\section{Acknowledgement}

This work was supported by the Korea Research Foundation Grant R04-2003-000-10031-0 funded by the Korean Government.

\section{References}

Anderson DM, Maraskovsky E, Billingsley WL, Dougall WC, Tometsko ME, Roux ER, Teepe MC, DuBose RF, Cosman D, Galibert L. A homologue of the TNF receptor and its ligand enhance T-cell growth and dendritic-cell function. Nature 1997;390:175-9

Arron JR, Vologodskaia M, Wong BR, Naramura M, Kim N, $\mathrm{Gu} \mathrm{H}$, Choi Y. A positive regulatory role for $\mathrm{Cbl}$ family proteins in tumor necrosis factor-related activation-induced cytokine (trance) and CD40L-mediated Akt activation. J Biol Chem 2001;276:30011-7

Bharti AC, Takada Y, Shishodia S, Aggarwal BB. Evidence that receptor activator of nuclear factor (NF)-kappaB ligand can suppress cell proliferation and induce apoptosis through activation of a NF-kappaB-independent and TRAF6-dependent mechanism. J Biol Chem 2004;279:6065-76

Belibasakis GN, Johansson A, Wang Y, Chen C, Kalfas S, Lerner UH. The cytolethal distending toxin induces receptor activator of NF-kappaB ligand expression in human gingival fibroblasts and periodontal ligament cells. Infect Immun 2005;73:342-51

Choi Y, Kim JJ. B cells activated in the presence of Th1 cytokines inhibit osteoclastogenesis. Exp Mol Med 2003; 35:385-92

Fox SW, Chambers TJ. Interferon-gamma directly inhibits TRANCE-induced osteoclastogenesis. Biochem Biophys Res Commun 2000;276:868-72

Glowacki J, Jasty M, Goldring S. Comparison of multinucleated cells elicited in rats by particulate bone, polyethylene, or polymethylmethacrylate. J Bone Miner Res 1986;1:327-31
Goldring SR, Roelke M, Glowacki J. Multinucleated cells elicited in response to implants of devitalized bone particles possess receptors for calcitonin. J Bone Miner Res 1988; 3:117-20

Janeway Jr. CA, Travers P, Walport M, Shlomchik MJ. Immunobiology, 6th Ed, 2005, Garland Science, New York and London, USA and UK

Josien R, Wong BR, Li HL, Steinman RM, Choi Y. TRANCE, a TNF family member, is differentially expressed on $T$ cell subsets and induces cytokine production in dendritic cells. J Immunol 1999;162:2562-8

Josien R, Li HL, Ingulli E, Sarma S, Wong BR, Vologodskaia M, Steinman RM, Choi Y. TRANCE, a tumor necrosis factor family member, enhances the longevity and adjuvant properties of dendritic cells in vivo. J Exp Med 2000;191: 495-502

Kong YY, Yoshida H, Sarosi I, Tan HL, Timms E, Capparelli C, Morony S, Oliveira-dos-Santos AJ, Van G, Itie A, Khoo W, Wakeham A, Dunstan CR, Lacey DL, Mak TW, Boyle WJ, Penninger JM. OPGL is a key regulator of osteoclastogenesis, lymphocyte development and lymph-node organogenesis, Nature 1999;397:315-23

Krukowski M, Kahn AJ. Inductive specificity of mineralized bone matrix in ectopic osteoclast differentiation. Calcif Tissue Int 1982;34:474-9

Lacey DL, Timms E, Tan HL, Kelley MJ, Dunstan CR, Burgess T, Elliott R, Colombero A, Elliott G, Scully S, Hsu H, Sullivan J, Hawkins N, Davy E, Capparelli C, Eli A, Qian YX, Kaufman S, Sarosi I, Shalhoub V, Senaldi G, Guo J, Delaney $\mathrm{J}$, Boyle WJ. Osteoprotegerin ligand is a cytokine that regulates osteoclast differentiation and activation. Cell 1998; 93:165-76

Lohmann-Matthes ML, Emmendoerffer A, Hao L. Influence of interleukin-2 on the differentiation of macrophages. Pathobiology 1991;59:117-21

Lyons $A B$. Analysing cell division in vivo and in vitro using flow cytometric measurement of CFSE dye dilution. J Immunol Methods 2000;243:147-54

Miyamoto T, Arai F, Ohneda O, Takagi K, Anderson DM, Suda T. An adherent condition is required for formation of multinuclear osteoclasts in the presence of macrophage colony-stimulating factor and receptor activator of nuclear factor kappa B ligand. Blood 2000;96:4335-43

Sakai H, Kobayashi Y, Sakai E, Shibata M, Kato Y. Cell adhesion is a prerequisite for osteoclast survival. Biochem Biophys Res Commun 2000;270:550-6

Sankar U, Patel K, Rosol TJ, Ostrowski MC. RANKL coordinates cell cycle withdrawal and differentiation in osteoclasts through the cyclin-dependent kinase inhibitors p27KIP1 and p21CIP1. J Bone Miner Res 2004;19:1339-48

Shin JH, Kukita A, Ohki K, Katsuki T, Kohashi O. In vitro differentiation of the murine macrophage cell line BDM-1 into osteoclast-like cells. Endocrinology 1995;136:4285-92

Shin MM, Kim YH, Kim SN, Kim GS, Baek JH. High extracellular $\mathrm{Ca} 2+$ alone stimulates osteoclast formation but inhibits in the presence of other osteoclastogenic factors. 


\section{Exp Mol Med 2003;35:167-74}

Tiranathanagul S, Yongchaitrakul T, Pattamapun K, Pavasant P. Actinobacillus actinomycetemcomitans lipopolysaccharide activates matrix metalloproteinase-2 and increases receptor activator of nuclear factor-kappaB ligand expression in human periodontal ligament cells. J Periodontol 2004;75: 1647-54

Tokalov SV, Henker Y, Schwab P, Metz P, Gutzeit HO. Toxicity and cell cycle effects of synthetic 8-prenylnaringenin and derivatives in human cells. Pharmacology 2004;71: 46-56

Udagawa N, Takahashi N, Akatsu T, Tanaka H, Sasaki T, Nishihara T, Koga T, Martin TJ, Suda T. Origin of osteoclasts: mature monocytes and macrophages are capable of differentiating into osteoclasts under a suitable microenvironment prepared by bone marrow-derived stromal cells. Proc Natl Acad Sci USA 1990;87:7260-4

Wong BR, Rho J, Arron J, Robinson E, Orlinick J, Chao M, Kalachikov S, Cayani E, Bartlett $3^{\text {rd }}$ FS, Frankel WN, Lee SY, Choi Y. TRANCE is a novel ligand of the tumor necrosis factor receptor family that activates c-Jun N-terminal kinase in T cells. J Biol Chem 1997a;272:25190-4

Wong BR, Josien R, Lee SY, Sauter B, Li HL, Steinman RM, Choi Y. TRANCE (tumor necrosis factor [TNF]-related activa- tion-induced cytokine), a new TNF family member predominantly expressed in T cells, is a dendritic cell- specific survival factor. J Exp Med 1997b;186:2075-80

Wong BR, Besser D, Kim N, Arron JR, Vologodskaia M, Hanafusa $H$, Choi Y. TRANCE, a TNF family member, activates $A k t / P K B$ through a signaling complex involving TRAF6 and c-Src, Mol. Cell 1999;4:1041-9

Xing L, Venegas AM, Chen A, Garrett-Beal L, Boyce BF, Varmus HE, Schwartzberg PL. Genetic evidence for a role for Src family kinases in TNF family receptor signaling and cell survival. Genes Dev 2001;15:241-53

Yasuda H, Shima N, Nakagawa N, Yamaguchi K, Kinosaki M, Mochizuki S, Tomoyasu A, Yano K, Goto M, Murakami A, Tsuda E, Morinaga T, Higashio K, Udagawa N, Takahashi N, Suda T. Osteoclast differentiation factor is a ligand for osteoprotegerin/osteoclastogenesis-inhibitory factor and is identical to TRANCE/RANKL. Proc Natl Acad Sci USA 1998;95:3597-602

Zhang X, Aubin JE, Kim TH, Payne U, Chiu B, Inman RD. Synovial fibroblasts infected with Salmonella enterica serovar Typhimurium mediate osteoclast differentiation and activation. Infect Immun 2004;72:7183-9 